\title{
Cultural keywords in World Englishes: A GloWbE-based study*
}

\section{Peter Collins, University of New South Wales}

\section{$1 \quad$ Introduction}

The concept of frequent words that are 'key' to specific cultures was developed by Williams (1976), who examines the etymological and cultural development of more than a hundred 'familiar' words such as art, bureaucracy, culture, nature and society. Subsequently Stubbs developed the use of corpora to analyse the habitual patterns associated with "cultural keywords'; i.e. words "which capture important social and political facts about a community" (Stubbs 1996:172). Stubbs claims - and this is taken for granted in the present exploratory study that the identification of keywords will always involve intuition. Accordingly, in studies of culturally distinctive keywords - such as those by Leech and Fallon (1992), Wierzbicka (1997), Ooi (2000), Teubert (2001), Oakes (2003), and Mukherjee and Bernaisch (2015) - there is no objective discovery procedure for the selection of keywords, although frequency information is typically used to check whether candidate keywords are 'common'.

The immediate inspiration for this study was Leech and Fallon's (1992) study (henceforth LF) of vocabulary differences between the Brown Corpus of American English (Brown) and the Lancaster-Oslo/Bergen Corpus of British English (LOB), which they assumed to reflect cultural differences between the United States and Britain. LF's study was in turn inspired by Chapter 8 of Hofland and Johansson (1982), a parallel alphabetical word frequency list of both the Brown and LOB corpora, and more specifically by Hofland and Johansson's discussion on pp. 32-40 of some of the vocabulary differences that seem to "invite explanation" (e.g. the suggestion of more extreme 'masculinity' in Brown, where he, boy and man are more fully represented, than in LOB, where she, girl and woman are more fully represented). Accordingly, LF's basic premise is that "Significant differences of vocabulary between the two corpora are unlikely to be due to accidents of sampling, and therefore other explanations for these differences (e.g. cultural reasons) can reasonably he sought." (p. 31). 
LF concede that their study has some limitations deriving from the size and composition of their 'Brown family' corpora, which I seek to address in the present study through the selection of the Global Web-based English Corpus (GloWbE) as database. There are three key differences between LOB and Brown, and GloWbE: LOB and Brown are restricted to written (printed) language only, whereas GloWbE contains both electronically 'written' and 'speech-like' texts; LOB and Brown are restricted to a particular historical period (the year 1961), whereas GloWbE is a contemporary (2012-2013) corpus; and LOB and Brown are restricted in size to only one million words each, whereas GloWbE contains almost 2 billion words (of which 1,224,948,043 words were used in the present study). The strengths and weaknesses of GloWbE are discussed in more detail in Section 2.

Following LF, my interest was not in merely linguistic differences between the varieties (e.g. American color vs British colour; American movie vs British film). ${ }^{1}$ Rather it was in non-linguistic contrasts, and more specifically those that are suggestive - or potentially suggestive - of broadly cultural differences or domains (e.g. the relatively high frequency of military and warfare in the American data, most likely reflecting the large size and power of the US military). The study is based on the assumption - as in LF - that national keyword frequencies will tend to reflect the degree of text producers' interest in and/or familiarity with and/or engagement with and/or preoccupation with the denotata of those words. In turn it is assumed that the nature of such interests, familiarities, engagements and preoccupations will in many cases be related to the standardised concepts and ideas - or 'stereotypes' - associated with national cultures. Such stereotypes can be amorphous, even contradictory, formed as they are not only by the opinions of the inhabitants of a country but also by what others believe to be true of that country. Consider LF's concluding generalisation on the picture of US and British culture in the 1960s that is suggested by their study:

we may propose a picture of US culture in 1961 - masculine to the point of machismo, militaristic, dynamic and actuated by high ideals, driven by technology, activity and enterprise - contrasting with one of British culture as more given to temporizing and talking, to benefitting from wealth rather than creating it, and to family and emotional life, less actuated by matters of substance than by considerations of outward status. However much of a caricature, this is not an unconvincing portrayal for those of us who have lived with or in both cultures through recent decades. (pp. 44-45) 
The present study is based on the same set of fifteen categories as found in LF (the first two rather 'concrete', the remainder less so, representing major sectors of public sociocultural life), plus an additional, sixteenth, category: (1) Sport; (2) Transport and Travel; (3) Administration and Politics; (4) Social hierarchy; (5) Military and Violence; (6) Law and Crime; (7) Business; (8) Mass media; (9) Science and Technology; (10) Education; (11) Arts; (12) Religion; (13) Personal reference; (14) Abstract concepts; (15) Ifs, buts, and modality. The additional category, "Forms of the auxiliary verbs be and have", was suggested by Oakes (2003) in a study that replicates the work of LF using the FLOB and Frown corpora (the updated 1990s equivalents of LOB and Brown respectively). For some categories I found it necessary to suggest subcategories thereof, in order to fruitfully explore the cultural implications of the findings (for religion: 'general' and 'Christian'; for personal reference: 'male', 'family' and 'individualism'; and for abstract concepts: 'grand abstractions' and 'emotions and attitudes').

Using the online resources of GloWbE, I obtained per million word (pmw) frequencies for sets of potentially culturally significant lexical items representing each category, including not just many from the LF study, but also relevant additional items gleaned from a variety of lexicographic sources. Two criteria were applied in the selection of items, both those featuring in the LF and Oakes studies and those that do not: (1) my judgement of their relevance to, and representativeness of, the category in question; and (2) a preliminary check that their frequencies were in the mid-to-high range of candidates for the domain in question. In the absence of any further reliable empirical criteria, it is conceded that there is an inevitable element of subjectivity in the procedure. Some potentially relevant items had to be excluded because only one of their senses was relevant to the category and, despite the availability of KWIC concordances provided by GloWbE tools, it was not feasible to manually cull irrelevant tokens. Thus, for example, status had to be eliminated from the social hierarchy (4) set because of the presence of a large number of tokens meaning 'state of affairs', unrelated to social standing.

A further difference between the LF study and the present one is the expansion in the number of English varieties studied from two to eight, enabling the paper to contribute more comprehensively to World Englishes research. Accordingly, the approach differs markedly from that of purely lexicographical studies insofar as the attestation of keywords in particular varieties is pursued vis-à-vis their prevalence in other varieties. The eight Englishes, selected from the twenty included in GloWbE, were: American English (AmE), British English (BrE), Australian English (AusE), New Zealand English (NZE), Singapore English (SingE), Hong Kong English (HKE), Indian English (IndE) and Kenyan English 
(KenE). Why these eight? They offer an even balance between Englishes belonging to what Kachru (1985) refers to as "Inner-Circle" (IC) countries, those where English is spoken and handed down as an L1 by the majority of the population, and "Outer-Circle" (OC) countries, those where English, which is mainly learned as an L2, is strongly rooted for historical reasons, has important internal functions, and is used commonly by many people in their daily lives. Within the IC, BrE and AmE are recognised as 'reference' varieties: the influence of BrE being in evidence in its role as colonial 'parent' in the evolution of postcolonial varieties including the remaining seven varieties in the list; the influence of AmE in evidence latterly in its strong impact on English worldwide, a reflection of the global dominance of the USA. AusE and NZE are included as established Southern Hemisphere varieties which, in view of the historical two-century interrelationship between the two Antipodean 'cousins', suggests that there may be some lexical co-patterning in the two varieties.

The three Asian OC varieties - IndE, SingE and HKE - have all been extensively studied. IndE, despite being largely irrelevant to the lives of the majority of India's population, is undoubtedly a major variety of English globally. Viewed from the perspective of Schneider's (2007) 'dynamic model of the evolution of Postcolonial Englishes', IndE today is undergoing 'phase 4' endonormativisation, as suggested by attitude survey evidence (e.g. Sahgal 1991; Kachru 1994; Gupta 2001). SingE has come to be, in the wake of Singapore's uprecedented post-Independence level of modernisation, economic growth, and nation building, "the means of expression of this newly emerging Asian-cumwestern culture." (Schneider 2007: 156). The exceptional status of English in Singapore, where every child is educated in English as a first language, has seen it progress to Schneider's final phase ('differentiation') in the view of a number of scholars (e.g. Hong 2014, Percillier 2016). The current state of HKE reflects the growth of Hong Kong since the 1960s into an entrepreneurial and commercial powerhouse and the emergence of a distinctive identity, one which as in Singapore combines Asian traditions such as family orientation with western values such as pragmatism and materialism (see Hyland 1997; Bolton 2003). KenE is included as a non-Asian OC variety. Presently KenE continues to nativise albeit as a linguistic marker of good education and a ticket to desirable professions - despite the fact that its spread is constrained by its coexistence with Kiswahili as a regional lingua franca and by various ethnic languages.

The structure of the remainder of the paper is as follows. Section 2 presents a critical overview of GloWbE, the data source for the study. Section 3 lists the research questions that the study addresses. Section 4 discusses the main study of keywords in the eight varieties modelled on LF's domain categories. Section 5 is devoted to a discussion of findings and concluding remarks. 


\section{The corpus data}

The present study makes use of the vast resources of GloWbE, thus enabling me to include items whose frequencies in smaller representative one million-word corpora of the type used by LF, Oakes (2003) and Oakes and Farrow (2007), would be statistically insignificant. Broadly speaking, GloWbE follows the design of the International Corpus of English (ICE) corpora, where about 60 percent of the total number of words for each country comes from transcriptions of spoken language, and the other 40 percent consists of more formal, written texts. Accordingly, in GloWbE, about 60 percent of the words for each country come from informal blogs and the other 40 percent from a wide variety of (often) more formal genres and text types such as newspapers, magazines, company websites, and so on (Davies and Fuchs 2015: 3-4; see also https:// 21 centurytext.wordpress.com/introducing-the-1-9-billion-word-global-webbased-english-corpus-glowbe/). Opinions differ on the extent to which the informality of blogs resembles that of the spoken word, with most prepared to accept that, while blogs may not be equivalent to speech, they are 'speech-like' in certain respects (see, e.g., Grieve et al. 2010; Squires 2010; Nelson 2015; Loureiro-Porto 2017; Mazzon 2019).

Despite the fact that the general representation of English varieties offered by GloWbE is limited to their use on the Net, and that the orality of its blogs is questionable, it is nevertheless currently the only corpus that is (readily) available to scholars needing copious amounts of data for comparative research on relatively low-frequency linguistic items in World Englishes. Where else but in GloWbE could one find parallel data of the following proportions for the eight English varieties examined in this study: GloWbE-US 386,809,355 words; GloWbEGB 387,615,074; GloWbE-AU 148,208,169; GloWbE-NZ 81,390,476; GloWbE-IN 96,430,888; GloWbE-SG 42,974,705; GloWbE-HK 40,450,291; and GloWbE-KE 41,069,085? A further advantage is that the search tools provided on the GloWbE website enable a wealth of quantitative information to be readily accessed, thereby obviating the need for the type of statistical procedures employed in early corpus-based studies, where chi-square tests were often used to identify words with significant frequency differences, as for example in LF (1992), Rayson, Leech and Hodges (1997), and Sardinha (2001). A helpful albeit somewhat general - suggestion of significance is provided by the five-way blue shading applied to the presentation of frequencies by the GloWbE tools, described by Mark Davies (pc) as representing, for each cell: "a function of the percentage (for that cell) compared to the highest value in the row - lightest blue for at least 20 percent, then 40 percent, then 60 percent, and then (darkest) 80 
percent or more". Figure 1 provides an example for the word beer, with frequencies presented pmw, from darkest to lightest: $80-100$ percent (CA, AU, NZ, SG); 60-80 percent (IE, ZA, TZ); 40-60 percent (US, GB, MY, PH, HK, KE, JM); 20-40 percent (IN, LK, NG, GH); 0-20 percent (PK, BD).

\begin{tabular}{|c|c|c|c|c|c|c|c|c|c|c|c|c|c|c|c|c|c|c|c|c|c|c|}
\hline \begin{tabular}{|l|} 
CONTEXX \\
\end{tabular} & ALL & PER MIL & us & $\stackrel{C A}{0}$ & $\stackrel{G B}{0}$ & IE & $\stackrel{A U}{0}$ & $\stackrel{\mathrm{NZ}}{\mathrm{N}}$ & $\stackrel{\mathbb{N}}{\mathbf{D}}$ & IK & $\begin{array}{l}\text { PK } \\
\mathrm{D}\end{array}$ & $\stackrel{\mathrm{BD}}{\mathrm{D}}$ & $\begin{array}{l}\text { SG } \\
\mathrm{O}\end{array}$ & MY & $\begin{array}{l}\mathrm{PH} \\
\mathbf{0}\end{array}$ & $\begin{array}{l}\mathrm{HK} \\
\mathbf{\mathrm { H }}\end{array}$ & $\begin{array}{l}\mathrm{ZA} \\
\mathbf{0}\end{array}$ & $\begin{array}{l}\mathrm{NG} \\
\end{array}$ & $\begin{array}{cc}G & G H \\
& \\
\end{array}$ & $\begin{array}{ll}\mathrm{KE} \\
\mathrm{U}\end{array}$ & $\begin{array}{ll}\mathrm{E} \\
\mathrm{B}\end{array}$ & $\mathrm{JM}$ \\
\hline BEER & 59458 & 31.29 & 30.54 & 47.53 & 30.07 & 34.37 & 45.9 & 53.2 & 16.44 & 413.98 & 85.78 & 10.03 & 344,12 & 227.45 & 1527,61 & 130.88 & $\begin{array}{ll}841.18 \\
\end{array}$ & $\begin{array}{ll}18 & 13.8\end{array}$ & & & $74 \quad 38.45$ & 528,84 \\
\hline
\end{tabular}

Figure 1: GloWbE frequencies (pmw) for beer

\section{Research questions}

This section presents a set of nine research questions that will be addressed in the study. They are as follows:

1. Do the results of the present study suggest a continuation or shift in relative key word preferences between $\mathrm{BrE}$ and AmE in the half-century between the sampling years for LF's Brown-family corpora (1961) and GloWbE $(2012 / 13)$ ?

2. Do the results reflect the close historical and current relationship between AusE and NZE?

3. Does the Kachruvian distinction between IC and OC countries provide a basis for interpreting the findings of the study, and if so for which categories?

4. Does Schneider's (2007) proposal of a dynamic evolutionary process in the formation of postcolonial Englishes provide a basis for interpreting the findings of the study, and if so for which categories?

5. Do the frequencies for individual varieties reflect their national stereotypes and/or cultural values?

6. Are there correlations between GloWbE frequencies and statistics available for real world phenomena?

In addition, there are several subsidiary questions to which answers were sought:

7. Do any of the results for the OC varieties reflect substrate influences and/or second-language acquisition simplification strategies?

8. Is there any evidence of skewing in the GloWbE data that might affect results?

9. When is it legitimate to offer generalisations pertaining to entire categories, and when is it not? 


\section{$4 \quad$ The findings}

This section presents the findings of the study of eight national varieties, along with comparisons to LF's (1992) - and Oakes' (2003) - US and British findings for each of their domain categories. For each category pmw frequencies were obtained for all items, and then the frequencies for each variety were averaged in order to determine the relative popularity of items across the eight varieties. The resulting frequencies were then listed in order from highest to lowest. ${ }^{2}$ In the case of five categories there was some danger of higher frequency items skewing these averages, especially some which had a small number of items, so for these I have shifted the focus away from total averages and provided a table of frequencies for all individual items in order to facilitate discussion of these instead. In these tables, and in average frequency lists, the pmw frequencies are normally taken to one decimal point (unless, as for example in Table 2, there are some identical frequencies and numbers are accordingly taken to two decimal points). Each category section - and in some cases subsections thereof - begins with a list of the items examined, and a list of average frequencies ordered from highest to lowest. In the frequency lists, and in subsequent discussion, for the sake of convenience the abbreviations used in GloWbE are used to refer to the relevant national subcorpora: thus 'SG' stands for GloWbE-SG (as opposed to 'SingE' for the English variety represented by SG, and 'Singapore' for the country; 'US' for GloWbE-US, vs 'AmE' and 'the USA'; and so on).

\subsection{Sport}

sport, sporting, game, winning, compete in

GB $91.5>$ US $68.8>$ AU 61.3 > IN 57.4 > NZ 53.9> SG 52.0 > KE 51.2 > HK 44.2

This category turned out to be rather uninteresting in LF, Oakes (2003), and the present study because, as is well known, some particular sports are played far more commonly in certain countries than in others: for example cricket has a US pmw frequency of merely 2.7 , there being little interest in or knowledge of this game in the USA, compared with 198.7 in IN, cricket being by far the most popular sport in India. While LF found a greater interest in sporting activities in the USA than in GB in their 1960s corpora, Oakes found this to no longer be the case in the parallel 1990s corpora.

In view of the largely predictable findings for individual sports, I turned my attention to the more general sports-related terms listed above. The ordering of varieties produced some expected results and at least one apparent surprise. The 
higher frequencies shown by the four IC countries than by the OC countries the respective average frequencies for the two subgroups being 68.9 and 51.2, the ratio $1.34: 1$ - can be plausibly interpreted as reflecting the typically more recreationally-oriented lifestyles of those living in the IC countries and the many sporting facilities they offer. By contrast, a surprising finding was the top ranking for BrE, whose frequency was well ahead of those for the other IC countries. This finding seemed counterintuitive to me until I recalled that the 2012 Olympic Games were held in London. So I searched Olympic in GloWbE and the resulting frequencies reinforced the importance of this event as a factor in the results for BrE in sport, the GB frequency of 70.2 being approximately double that for the variety with the second highest frequency, AusE (36.5).

\subsection{Transport and travel}

car, auto, aircraft, plane, aeroplane

HK $14.2>$ IN $13.3>$ NZ 10.32 > SG 10.27> US 10.2> AU 9.5> GB 9.4 > KE 9.0

LF noted a greater emphasis on travel and transport in Brown than in LOB, attributing the difference to the relative size of the USA. The Transatlantic difference was mild only in the GloWbE data, where linguistic differences were more marked than cultural differences (e.g. BrE prefers car while AmE prefers auto; BrE prefers aeroplane, while AmE prefers plane and strongly disprefers aeroplane and aircraft; the Antipodean varieties tend to pattern similarly, as in their strong mutual endorsement of car and plane). The present study certainly did not yield any correspondence between frequencies and land size, the areally miniscule Hong Kong and Singapore being in the top four countries, and the vast USA and Australia in the bottom four.

\subsection{Administration and politics}

citizens, nation, community, leadership, authority, patriotic, democracy, communism, socialism, climate change, global warming, terrorism, migrants, poverty, equality

KE 196.7 > AU 123.0 > US 113.6 > NZ 112.4 > IN 104.8> GB 91.2 > HK 89.9 $>$ SG 77.5

It is difficult to explain the exceptionally high KenE frequency, or the high ranking of AusE in the IC. Indeed for this domain the overall frequencies are less revealing than the individual items and some subgroupings thereof. Accordingly, for this category a complete set of frequencies is provided, in Table 1: 
Table 1: GloWbE pmw frequencies for administration and politics

\begin{tabular}{|c|c|c|c|c|c|c|c|c|}
\hline citizens & KE 103.3 & US 95.9 & SG 87.7 & IN 73.1 & HK 64.4 & GB 52.5 & AU 50.6 & NZ 50.1 \\
\hline nation & KE 191.5 & US 159.7 & IN 136.6 & AU 107.4 & GB 85.0 & SG 82.8 & NZ 76.5 & HK 72.2 \\
\hline community & KE 551.3 & AU 330.9 & NZ 312.5 & US 246.1 & HK 208.7 & GB 199.3 & IN 186.3 & SG 171.6 \\
\hline leadership & KE 190.5 & NZ 93.7 & IN 87.1 & HK 82.5 & AU 76.1 & SG 75.0 & US 71.0 & GB 64.0 \\
\hline authority & NZ 136.9 & KE 107.6 & IN 105.1 & HK 92.5 & AU 83.9 & GB 82.4 & US 77.9 & SG 65.6 \\
\hline patriotic & KE 7.7 & HK 6.5 & US 5.9 & IN 5.5 & GB 4.1 & $\mathrm{AU} 3.8$ & NZ 2.8 & SG 2.7 \\
\hline democracy & IN 76.3 & KE 70.7 & GB 59.8 & AU 56.3 & US 51.1 & HK 47.0 & NZ 42.0 & SG 29.3 \\
\hline communism & US 11.5 & GB 8.48 & AU 8.43 & HK 8.1 & IN $\quad 5.2$ & NZ 4.9 & SG 4.7 & KE 3.2 \\
\hline socialism & US 16.6 & HK 13.2 & AU 11.6 & GB 11.0 & NZ 9.0 & IN 7.7 & SG 4.4 & KE 3.8 \\
\hline $\begin{array}{l}\text { climate } \\
\text { change }\end{array}$ & KE 118.8 & AU 100.6 & NZ 48.9 & GB 44.5 & US 40.7 & IN 29.7 & HK 28.3 & SG 27.7 \\
\hline $\begin{array}{l}\text { global } \\
\text { warming }\end{array}$ & AU 48.8 & US 29.1 & NZ 20.3 & GB 15.9 & KE 12.3 & IN 10.6 & HK 7.6 & SG 6.7 \\
\hline terrorism & IN 30.5 & KE 24.9 & US 22.7 & GB 17.6 & AU 14.1 & NZ 10.8 & HK 10.3 & SG 7.3 \\
\hline migrants & KE 18.2 & AU 15.4 & NZ 14.1 & HK 12.7 & $\begin{array}{ll}\text { IN } & 9.9\end{array}$ & $\begin{array}{|ll|}\text { SG } & 8.1\end{array}$ & GB 7.9 & $\begin{array}{ll}\text { US } & 2.7\end{array}$ \\
\hline poverty & KE 170.1 & IN 54.0 & US 50.5 & NZ 47.9 & GB 47.5 & HK 44.1 & AU 36.6 & SG 33.6 \\
\hline equality & KE 29.9 & AU 29.5 & GB 28.49 & NZ 28.42 & US 27.1 & HK 21.5 & IN 21.1 & SG 12.4 \\
\hline
\end{tabular}

Both LF, and Oakes (2003), found that Americans favour participatory and patriotic politics (citizen(s), community/ies, leadership, nation(s), participation, public) while the British have a preference for authority (authority and authoritative). Our GloWbE frequencies suggest that this difference may have persisted closer to the Present Day, with citizens and nation being strong indicators, community, leadership and authority mild indicators. The findings for patriotic and democracy suggest that patriotism is a stronger cultural value in the USA than in Britain and Australia, while the British have a slightly stronger interest in democracy than the Americans and Australians. Americans have more interest in talking about communism and socialism (largely negatively, GloWbE KWIC concordances revealing that common collocates include fail, fight, defeat, combat, and danger), than do the British or Australians.

I included in this category some lexical items that relate to major political issues. There is strikingly more interest in climate change and global warming in AU than in US or GB (one factor most likely being the extensive discussion and debate in Australia surrounding the Gillard Government's introduction of its carbon pricing scheme - commonly dubbed by its critics as a 'carbon tax' - in 
July 2012), while the IC countries are generally more concerned with this issue than the OC countries. GloWbE frequencies suggest that terrorism was a hotter topic of discussion in 2012/2013 in the US than in GB or AU, presumably due mainly to Far Right Wing threats at home in the USA and Jihadist threats overseas. The results for migrants confirm the status of Australia as a multicultural nation, and at the same time one whose rapidly expanding population as a result of immigration is causing community concern. The extraordinarily low US frequency can be accounted for in large part by the American linguistic preference for immigrant over migrant (immigrants: US 28.4 vs AU 14.4). The results for poverty split the OC countries between those in which poverty is a major challenge (Kenya and India) and those where it is not (Hong Kong and Singapore). Meanwhile the figures for poverty suggest that in the IC poverty is invoked as a topic more frequently in the US texts than the others, with NZE and BrE not far behind, and relatively rarely in AusE. AusE leads the way in the IC with equality, in keeping with Australia's stereotypical embracing of this concept (see further Section 4.4 below), though the other three IC countries are close behind.

\subsection{Social hierarchy}

social class, upper class, middle class, working class

US $5.8>$ HK $4.7>$ GB $4.1>$ IN $3.8>$ KE $3.5>$ AU $3.0>$ NZ $2.4>$ SG 2.2

In view of the skewing of the total frequencies by the high frequencies for one item, middle class, individual frequencies are supplied (in Table 2). The consistently low AU frequencies for social class, upper class, and middle class support the stereotype of Australia as a classless, egalitarian, society (Australians being reputed to disrespect status and elitism, with their penchant for "cutting down the tall poppies": see for example Hornadge (1980: 94-103), and Moore (2008: 149)). More striking than this result is the consistent co-patterning of AU and NZ for all four items (see Nolan 2007) for discussion of the idea of egalitarianism as a cornerstone of New Zealand's national identity). By contrast, a greater degree of class consciousness was in evidence in GB (particularly in the result for social class), and US (particularly in the results for upper class and middle class), the latter finding arguably confirming the validity of LF's submission that "American society may not be so egalitarian" (p. 41). The strong frequencies for social class and upper class in HK are consonant with the stereotypical status-consciousness of Hongkongers (see https://culturalatlas.sbs.com.au/hong-kong-culture/hong-kong-culture-core-concepts), but that for working class in HK is a greater challenge to explain. 
Table 2: GloWbE pmw frequencies for social hierarchy

\begin{tabular}{|l|l|l|l|l|l|l|l|l|}
\hline social class & GB 1.9 & HK 1.7 & US 1.2 & KE 1.0 & SG 0.7 & NZ 0.68 & AU 0.63 & IN 0.5 \\
\hline upper class & US 2.0 & HK 1.7 & GB 1.52 & SG 1.51 & KE 1.49 & IN 1.40 & AU 1.2 & NZ 0.7 \\
\hline middle class & US 35.3 & IN 23.1 & KE 23.0 & HK 14.9 & GB 13.6 & SG 13.2 & AU 12.7 & NZ 8.9 \\
\hline working class & HK 19.0 & GB 16.0 & AU 9.4 & NZ 8.6 & US 8.0 & IN 5.2 & KE 2.5 & SG 2.2 \\
\hline
\end{tabular}

\subsection{Military and violence}

military, warfare, missiles, gun, kill, shot, murder

US $55.8>$ KE $38.4>$ GB $36.2>$ IN $34.4>$ NZ 29.8 > AU 29.7 > SG 28.0 > HK 25.0

As in LF, so in the present study, the US corpus figures prominently in this category. In 2012/2013, when GloWbE was being compiled, the USA was renowned for its large and powerful military, and continued to see itself as policeman of the world, particularly in Iran and Afghanistan. Not only does US have by far the highest total average frequency of all the subcorpora, it has the highest frequency for every item bar one (missiles), for which it has the second highest frequency. It is also unsurprising that HKE should have the lowest average frequency, Hongkongers being a traditionally peace-loving and non-violent people (hence the dilemma for many who in 2019, as anti-government protests became increasingly aggressive, saw their hopes of brokering peace diminishing: see https://www.scmp.com/news/hong-kong/society/article/3039261/dilemmapeaceful-rational-and-non-violent-hongkongers).

\subsection{Law and crime}

jail, sue, suicide, abortion

US $19.5>$ NZ $17.0>$ GB $14.5>$ AU $13.2>$ IN $10.8>$ KE $10.0>$ SG $6.9>$ HK 5.2

There is some overlap between this category and the previous one (gun, kill, shot and murder arguably being also relevant here). The present study confirmed the finding of LF, and Oakes, that terms relating to law and crime are more frequent in AmE than in BrE. Moving beyond the two reference varieties, we find the IC varieties, with their long-established legal and judicial systems, clearly dominating over the OC countries (by a ratio of 16.1:8.2, or approximately 2:1). Further generalisations about average frequencies are probably 
unwise, in view of the small number of lexical items for this category, so I shall offer several observations on the frequencies for individual items (see Table 3).

The high US and GB frequencies for jail probably reflect community concerns and publicity concerning the notoriously overcrowded and violent jails in these countries. The strong frequencies for suicide, abortion and sue in NZ reflect concerns in New Zealand with the issues and problems around suicide, abortion and sueing (prompted inter alia by the New Zealand Government's "New Zealand Suicide Prevention Action Plan 2008-2012"; high profile High Court cases in 2011 involving the Right to Life New Zealand movement and the Abortion Supervisory Committee; and a high profile High Court ruling in 2012 allowing Kim Dotcom to sue the Government Communications Security Bureau).

The very high figures for abortion in US presumably reflect the fact that abortion has long been an issue hotly debated by supporters and opponents in the USA. Curiously, the US frequency for suicide is smaller than that of the other three IC counties, despite the fact that the suicide rate in the US is ahead of that in Australia, New Zealand and Great Britain (according to lists published by the World Health Organisation; see https://www.who.int/mental_health/suicideprevention/extraction_suicide_statistics.pdf?ua=1). It is unclear why there should be a reluctance to confront and discuss suicide as a social issue in the USA. While in this case GloWbE frequencies do not correlate with real-word statistical information, in the case of suicide in IN the opposite is in evidence. As Patel et al. (2012) note, in India in 2012 suicide death rates were among the highest in the world, an observation which provides a source of explanation for the difference in strength between the high IN frequency (31.0) and the significantly lower other OC frequencies (KE 24.0, SG 14.1 and HK 13.7).

Table 3: GloWbE pmw frequencies for law and crime

\begin{tabular}{|l|l|l|l|l|l|l|l|l|}
\hline jail & US 46.5 & GB 44.9 & NZ 36.8 & IN 36.1 & AU 33.0 & KE 31.4 & SG 18.6 & HK 15.1 \\
\hline sue & NZ 21.4 & GB 16.7 & AU 16.5 & SG 15.6 & US 15.3 & KE 9.1 & HK 8.2 & IN 4.8 \\
\hline suicide & NZ 35.9 & AU 31.7 & IN 31.0 & US 30.3 & GB 29.0 & KE 24.0 & SG 14.1 & HK 13.7 \\
\hline abortion & US 63.6 & NZ 41.6 & GB 25.2 & AU 24.5 & KE 15.8 & IN 14.4 & SG 7.6 & HK 4.9 \\
\hline
\end{tabular}

\subsection{Business}

economy, tax, trade, market, rich, wealth and money

HK $240.3>$ SG $202.8>$ KE $198.8>$ IN $181.3>$ US $181.0>$ AU $168.6>$ GB $165.4>\mathrm{NZ} 165.2$ 
In this category it is the OC varieties, especially Hong Kong and Singapore with their thriving economies (as noted in Section 1) and their reputation for being concerned with personal wealth and status, that dominate over the IC group, by a ratio of 205.8:170.1, or 1.2:1. India and Kenya have also enjoyed solid economic growth, albeit less spectacular. In 2012 the Indian economy had a growth rate (measured in terms of GDP growth) of 0.22 percent and in 20 percent 13 of 0.93 percent while for Kenya the corresponding growth rates were -1.55 percent and 1.32 percent. (See: https://www.macrotrends.net/countries). Within the IC it is the USA that dominates, reflecting perhaps its role as an economic superpower, a situation that appears not to have changed since the 1960 s, in view of LF's reference (p. 41) to 'terminological contrasts' indicative of attitudes underlying the economic dominance of the USA and the post-war commercial decline of the UK.

\subsection{Mass media}

facebook, television, newspapers, advertising

IN $34.0>$ US $31.3>$ SG $31.1>$ AU $30.8>$ GB 29.6 > NZ 29.0 > HK 28.4 > KE 24.5

As in the LF study, AmE outstrips BrE, but the GloWbE differences are slight. Apart from advertising, for which frequency information on advertisements is sparse, individual items yield more culturally-relevant findings. The GloWbE frequencies for facebook were considered in light of figures available on the Web (see for example https://www.statista.com/statistics/268136/top-15-countries-based-on-number-of-facebook-users/) for Facebook user numbers per country in 2019/2020, in conjunction with population figures, which yield the following ordering of our eight countries determined by approximate population percentages: Singapore 80 percent $>$ UK 67 percent $>$ Hong Kong 61 percent $>$ New Zealand 60 percent $>$ Australia 58 percent $>$ USA 54 percent $>$ India 18 percent $>$ Kenya 14 percent. There are some loose correlations here with the frequencies in Table 4 (in which SG is in near-top position, and KE near-bottom), but also some striking non-correlations (with India in top position, and Hong Kong at the bottom). In the case of the latter possible explanations are: in India about half of all Facebook interaction occurs using English but only about one in ten Indians speak English; and in Hong Kong blog references to Facebook are likely to be constrained by strong resistance from the PRC to the social networking platform). 
As for television, reliable and consistent statistics on viewing consumption are hard to obtain, and there are only partial correlations with GloWbE frequencies. Sources include: https://www.statista.com/statistics/276748/average-dailytv-viewing-time-per-person-in-selected-countries/; and https://www.worldatlas.com/articles/which-country-watches-the-most-tv.html. Suffice it to say that of the countries represented in this study the USA and Singapore are at opposite extremes, with Americans the most prolific viewers and Singaporeans the least. In the case of the USA this statistic does not correlate with the mid-range popularity of television in GloWbE, but in the case of Singapore it does.

The average frequency for newspapers (24.3) is outstripped by that for television across the eight varieties (56.5) by a ratio of 2.3:1, the difference presumably related to the fact that while television consumption has remained relatively stable over the past decade, time spent reading newspapers has almost halved (see https://www.statista.com/statistics/256296/distribution-of-media-timeworldwide/). It is notable that the high frequency for newspapers in GB is in line with circulation figures for newspapers and periodicals per capita in 2000 (published online by Nation Master (https://www.nationmaster.com/country-info/ stats/Media/Newspapers-and-periodicals/Circulation/Daily/Per-capita) which have the UK significantly higher than the other three IC countries.

Table 4: GloWbE pmw frequencies for mass media

\begin{tabular}{|l|l|l|l|l|l|l|l|l|}
\hline facebook & IN 130.8 & SG 130.0 & US 127.3 & AU 108.6 & GB 97.9 & NZ 95.6 & KE 78.3 & HK 73.8 \\
\hline television & IN 63.2 & GB 61.3 & NZ 60.4 & AU 59.7 & US 59.6 & HK 58.9 & KE 47.3 & SG 41.3 \\
\hline newspapers & GB 28.1 & IN 28.0 & KE 26.2 & AU 25.8 & HK 25.0 & SG 21.4 & US 21.0 & NZ 18.6 \\
\hline advertising & HK 69.3 & NZ 57.5 & SG 56.2 & AU 51.9 & IN 50.0 & GB 49.5 & KE 44.1 & US 42.5 \\
\hline
\end{tabular}

\subsection{Science and technology}

science, technology, electronic, digital

HK $74.1>$ IN $63.6>$ AU59.7 > US 59.0 > KE 54.9> NZ 54.0 > SG 53.01 > GB 52.96

While the overall averages are well-nigh uninterpretable, the separate results for science and technology (the latter interpreted as embracing technology, electronic and digital), display a clear demarcation between the IC vs OC. While science is dominated by the IC countries (144.8:124.4, or 1.5:1), technology is dominated by the OC countries (391.7:266.5, or 1.5:1), with technology displaying the strongest ratio (1.8:1). Within the OC Hong Kong is a clear leader, pre- 
sumably a reflection of the well-known fascination of Hongkongers with electronic/digital technology (see https://www.enotes.com/homework-help/whatpercentage-hong-kongs-population-technology-431781). As is often the case the two Antipodean varieties, AusE and NZE, perform similarly.

Table 5: GloWbE pmw frequencies for science and technology

\begin{tabular}{|l|l|l|l|l|l|l|l|l|}
\hline science & AU 211.4 & US 208.2 & NZ 173.6 & HK 156.7 & IN 148.4 & GB 146.0 & KE 100.9 & SG 91.6 \\
\hline technology & HK 281.3 & KE 240.3 & IN 240.2 & SG 198.2 & US 157.2 & AU 151.1 & GB 149.8 & NZ 142.7 \\
\hline electronic & HK 67.2 & IN 45.7 & SG 39.7 & KE 38.0 & NZ 37.1 & AU 35.5 & GB 35.1 & US 34.1 \\
\hline digital & SG 94.6 & GB 92.8 & HK 87.6 & AU 79.3 & NZ 78.4 & IN 74.1 & US 72.8 & KE 59.8 \\
\hline
\end{tabular}

\subsection{Education}

education, university, college, teacher, study, classroom

HK $147.2>$ KE $144.1>$ US $114.0>$ NZ $112.5>$ IN $111.0>$ GB $97.1>$ SG 94.1 $>$ AU 75.2

There are two contrasts in the frequencies that invite explanation. One is the stronger result for the US than for GB, a difference also noted by LF, and Oakes (2003), whose studies noted greater American awareness of the importance of education, particularly university education, in line with the greater proportion of the population earning university degrees in the USA than in the UK (see https://www.statista.com/statistics/232951/university-degree-attainment-bycountry/). The second difference, the significantly stronger result for NZ than for AU, can be explained in the same way. Further factors may be the attractiveness of New Zealand to prospective international university students based inter alia on its quality of education and low cost of living and/or the well-known reputation of Australians for anti-intellectualism (as commonly observed in the media, for example

http://www.dailylife.com.au/news-and-views/dl-opinion/why-australia-hatesthinkers-20130513-2jhis.html;

https://www.theage.com.au/national/victoria/is-antiintellectualism-killing-thenational-conversation-20150801-gipidj.html

https://www.smh.com.au/business/small-business/we-love-being-dumb-anddumber-20150108-3nraf.html).

The results for university and college suggest a linguistic rather than cultural difference for these tertiary educational institutions. The term college is used widely in the USA for post-secondary education, while the term university is more specific and used comparatively less commonly, a difference that is 
reflected in as the US results. This pattern contrasts with that in the GB frequencies where - relative to the US results - college is dispreferred but university is preferred. College has fallen into desuetude in Australia and New Zealand, where most teacher's colleges have been integrated into the university system.

The strong HK result most likely reflects the renowned Hong Kong obsession with education, teachers and study, and in particular the high value that families in Hong Kong place on student achievement and success in school.

\subsection{Arts}

opera, orchestra, arts, sculpture, literature

HK $22.9>$ NZ $15.9>$ AU $15.48>$ SG $15.46>$ GB $14.6>$ IN $13.9>$ US $13.3>$ KE 9.3

The very strong HK frequency most likely reflects the increasing prominence that the role of art and "high culture" have taken on since China resumed sovereignty over the territory (see Clarke 2002). Unsurprisingly the inhabitants of Kenya - a 'third world', or perhaps 'developing', nation - display little interest in high culture. The low US frequency suggests that Americans, more familiar with "popular" or "common" culture (see https://www.britannica.com/place/ United-States/History), may be somewhat averse to high culture. The only item that was comparatively frequent in US was literature, a curious finding given that in the LF study the US was found to have a predilection for the performing arts rather than for books. The arts category is yet another for which the AU and NZ results were remarkably close.

\subsection{Religion}

For this category I selected two sets of words: 'General', and 'Christianityrelated'.

(i) General religion terms: pray, religion, God

KE $117.5>$ US $88.5>$ NZ 77.9 > IN $66.4>$ AU 57.0 > GB 43.0 > SG $40.1>$ HK 34.8

Wikipedia provides a list based upon global Gallup Poll research on the importance of religion by country, which was conducted in 2009 and in which the question asked was: "Is religion important in your daily life?" (see https:// en.wikipedia.org/wiki/Importance_of_religion_by_country). The results for our eight countries were: Kenya 94 percent $>$ India 90 percent $>$ Singapore 7 percent $>$ USA 69 percent $>$ New Zealand 33 percent $>$ Australia 32 percent $>$ UK 27 
percent $>$ Hong Kong 24 percent. A comparison of this list with that of our general religion GloWbE frequencies reveals a number of correlations: Kenya is both the most religious country and that in which religion is more topical in blogs than in the other countries. The reverse is the case in Hong Kong. Apart from this there are some loose correlations (e.g. the USA) and some non-correlations (New Zealand and Singapore).

(ii) Christianity-related terms: Christ, Jesus

KE $39.0>$ NZ $34.5>$ US $34.4>$ AU $23.0>$ GB $14.5>$ HK $13.4>$ SG $12.8>$ IN 11.3

These frequencies correspond quite closely - with the single exception of New Zealand - with census-derived percentages of Christians per country cited in Wikipedia statistics, the latter indicative only because there is some variation in the census years sampled (see https://en.wikipedia.org/wiki/ Christianity_by_country): Kenya 70 percent $>$ USA 65 percent $>$ GB 53.6 percent $>$ Australia 52.1 percent $>$ New Zealand 49 percent $>$ Singapore 18 percent $>$ Hong Kong 11.8 percent $>$ India 2.3 percent.

The remaining three categories (13-16) seem to lie on more general and abstract ground. Any explanatory comments here must of necessity be somewhat speculative.

\subsection{Personal reference}

Items for this category were subdivided into three sets: 'male', 'family' and 'individual'.

Male terms: he, him, his, man

GB $1156.0>$ US 1149.4 > IN 1076. $3>$ KE 1015.5 > SG 933.5 > AU 885.0 > NZ $832.8>$ HK 802.4

While LF (p. 43) reported the USA to be more "male-oriented" than the UK (using figures taken from Hofland and Johansson, p. 38), Oakes's (2003: 220) findings indicated that the US masculine bias was no longer apparent in the 1990s corpora. The 1990s situation appears to have persisted, with GB and US frequencies extremely close. Rather surprisingly, in view of the stereotypical masculinism that is associated with the stereotypes of the two Antipodean countries (Dyrenfurth 2015; Ford 2018), AusE and NZE have relatively low frequencies. 
(ii) Family terms: father, mother, marry, marriage

KE $136.9>$ IN $128.4>$ AU $125.7>$ NZ $124.3>$ US $122.3>$ SG $114.1>$ HK $110.4>$ GB 107.0

In the LF study BrE was found to be more oriented than AmE to family relationships. However GloWbE frequencies indicate the reverse to be, or to have become, the case. The two poorest OC countries, Kenya and India, are the most family-/marriage-oriented, followed by the three IC countries (the USA, Australia, New Zealand and the USA). The least family-/marriage-oriented country, by a large margin, was the UK. Perhaps this relates to the extent of reportedly changing expectations in the UK regarding the archetypal family (https://culturalatlas.sbs.com.au/british-culture/british-culture-family).

Individual terms: self, myself, $I$, me

AU $55.0>$ US $54.5>$ SG 53.7 > GB 50.6 > KE $48.8>$ NZ $46.8>$ IN $39.0>$ HK 37.0

The AU frequency for pronouns relating to the individual/self is compatible with Australia's reputation as a highly individualist culture in which self-reliance and initiative are prized attributes (Rosenthal 1989; Hofstede 2001; Wang 2003). Unsurprisingly, in view of the dominance of capitalist ideology in the USA, the US frequency is close to that for AU. The two South-East Asian countries are at opposite extremes: the low-scoring Hong Kong embraces the Chinese (Confucian) practices of 'selflessness' and 'collectivism', while the highscoring Singapore - despite its predominantly Chinese population - embraces individualism and 'guided capitalism' (with its support of free trade and the international circulation of capital abroad: see Wee 1999). ${ }^{3}$

\subsection{Abstract concepts}

LF found - as did Oakes - that while AmE embraces grand abstractions more than BrE, particularly those representing the ideals of a democratic society, BrE prefers abstract categories representing emotions and attitudes. The distinction between the two types of abstract concepts was found to be relevant in the present study as well.

$$
\text { Grand abstractions }
$$

freedom, liberty, independence, justice, integrity, ethics, morality, truth

KE $73.2>$ US $68.7>$ IN $60.1>$ GB 52.1 > AU 51.8> NZ 49.8> SG $34.3>$ HK 29.7 
The frequencies for the 'grand abstractions' indicate a continuation of the American predisposition towards grand abstractions, in line with their enshrinement in the American Constitution. By contrast, the stereotypical apoliticism of Hongkongers (as assumed for example in a letter about the 2019 protests, published in the South China Morning Post on December $10^{\text {th }} 2019$, recommending that "Hongkongers should accept that their apolitical 'sheltered lives' have ended" (https://www.scmp.com/comment/letters/article/3041243/protestsmean-hongkongers-should-accept-their-apolitical-sheltered), and the traditional pragmatism of Singaporeans (see Somjee and Somjee 1995; Tan 2012), may explain the very low HK and SG frequencies. Finally, the closeness of the (moderate) results for the Antipodean varieties is again notable.

\section{Emotions and attitudes}

disgust, doubt, goodwill, happiness, happy, sad, lucky, enjoy, fun, jealousy, laugh, love, hate, good, nice

SG $428.9>$ US $341.8>$ AU $338.4>$ GB $327.7>$ NZ $315.9>$ IN $298.7>$ HK $276.2>$ KE 267.3

What is perhaps most striking here is the SG result, which sets Singapore apart from the other OC countries, and closer to - in fact well ahead of - the four IC countries, residents of which appear to have little problem with talking about emotions and attitudes, especially Americans and Australians.

In the case of this category, as in others, the question of the relationship between GloWbE frequencies and real-world statistics is a vexed one. For example happiness is an emotion for which empirical inter-national information is available. The World Happiness Report is an annual publication of the United Nations that presents rankings of 'national happiness' based on respondent ratings of informants' own lives, which also correlates with various life factors. In 2012 the rankings for our eight (out of 156) countries were: NZ $8^{\text {th }}>$ Australia $11^{\text {th }}>$ UK $15^{\text {th }}>$ US $19^{\text {th }}>$ Singapore $34^{\text {th }}>$ Hong Kong $76^{\text {th }}>$ Kenya $121^{\text {st }}>$ India $140^{\text {th }}$. The four 'happiest' countries were the IC set, and yet they used the word happiness the least; the four least happy countries were the OC set, and yet they used the word happiness the most (outscoring the IC by a ratio of 1.5:1). Further confounding these non-correlations is the finding that the frequencies for happiness were misaligned with those for the cognate adjective happy: GloWbE frequencies for happy in the IC (780.1) and the OC (802.4) were very similar. 


\subsection{Ifs, buts, and modality}

if, unless, but, although, though, maybe, perhaps, possibly

US $1235.6>$ GB $1234.8>$ NZ 1194.7 > AU 1113.8 > IN 988.9> KE 859.6 > SG $652.5>$ HK 616.5

The frequencies for some items in this category reflect 'merely linguistic' intervarietal differences. The most obvious example is the contrast between the British preference for perhaps over the synonymous maybe, and the American preference for maybe over perhaps. The results of the present study - with GB and US almost identical in their average frequencies - differ from those of LF, who describe a UK tendency towards indecisiveness, and equivocation, referring to "the wishy-washy Briton who lacks firmness and decisiveness, seeing two sides to every question, and shades of grey instead of black and white." (1992: 44).

The four IC countries as a group have a significantly higher average frequency (1197.2) than the OC (779.4), the ratio being approximately 1.5:1. If, following LF's lead, we depict the residents of the IC countries as wishy-washy hedgers and temporisers, we might equally well criticise the residents of the OC countries - especially Hong Kong and Singapore - for the putative bluntness and directness of their speech styles. The identification of an IC vs OC contrast here arguably derives support from the findings of a number of academic studies. For example, Hackert et al. (2013) find the frequencies of might, 'dynamic/ epistemic' could, and hypothetical could, to be significantly higher in ICE-GB than in ICE-India and ICE Singapore. Klimova (2014) reports that one thing that non-native speakers find difficult when learning English is the use of tentative language (i.e 'hedging', or 'vague language'). The finding by Chen (2017) that Anglophone academic English writers used more hedges than their Chinese counterparts is relevant if we can extrapolate from his subjects to the broader IC and OC groupings.

\subsection{Forms of the auxiliary verbs be and have}

has, have, had, is, was, were

US 484,017 > GB 403,274 > NZ 398,053 > AU 317,791 > IN 214,666 > HK $180,351>$ SG 150,283 > KE 141,048

The final category is somewhat different from the other fifteen, insofar as it involves 'closed class', or 'function', words rather than 'open class', or 'content', words. Following Oakes (2003), whose findings for auxiliary be and have were consistent with the frequencies reported by Hofland and Johansson (1982: 
36), I have included this category on the grounds that it reveals a striking linguistic contrast between the IC and OC groups.

The GloWbE frequencies provided - pmw totals for has, have, had, is, was and were followed directly by a verb form, based on the top 100 combinations contrast with the finding of Hofland and Johansson, and Oakes, that forms of (auxiliary) be and have were more common in BrE than AmE, indicating instead a stronger preference for these items in AmE over BrE, by a ratio of 1.2:1. Furthermore, in the present study, AmE has a strikingly higher frequency than the other three IC varieties, and AusE a strikingly lower frequency than the other three.

The ratio for the IC vs OC groups $(1,603,135: 689,348$, or 2.3:1) was strongly biased in favour of the IC. There are two possible explanations for the OC result. The first is that the local 'substrate' languages that have contributed to the formation of the OC Englishes tend to have syntactically simpler tense/ aspect systems. The variable omission of verbal auxiliaries in SingE, especially the colloquial variety that is often referred to as 'Singlish' is ascribable to Chinese and Malay substrate influence (Alsagoff and Lick 1999; Leimgruber 2011). In Cantonese, substrate for HKE, affixes are used to express (progressive and perfect) aspect (Matthews and Yip 2011). In Swahili, substrate for KenE, tense and aspect are also marked morphologically. The only World English that bucks the OC trend is IndE, which has the second highest average frequency overall. In Hindi, a major substrate language for IndE, aspect is marked morphologically but auxiliaries are nevertheless used to mark tense.

The second possible explanation for the OC result is that second-language learners tend to use a use a simplified form of language, a strategy that Richards (1974) views as resulting from learners seeking to communicate via a limited number of forms or rules: "the learner generates a grammar in which many of the marked-unmarked, distinctions of the target language are removed, where inflected forms tend to be replaced by uninflected forms, and where preposition, auxiliary and article usage tend to be simplified" (1974: 71). An example of auxiliary omission is the following, from GloWbE-SG: "I also had spotting realy loght a week ago ... we been trying for a baby".

\section{Discussion and conclusion}

This section summarises the information relevant to the research questions (repeated below) that were posed in Section 3. 
1. Do the results of the present study suggest a continuation or shift in relative key word preferences between $\mathrm{BrE}$ and $\mathrm{AmE}$ in the half-century between the sampling years for LF's Brown-family corpora (1961) and GloWbE (2012/13)?

The following observations are offered with the caveat that compositional differences between the GloWbE and LOB/Brown corpora oblige us to exercise caution in identifying similarities and differences between the findings of the present study and the LF study. Findings which suggest the enduring validity of LF's findings are: the contrast between the American preference for participatory and patriotic politics and the British preference for authority (3); the dominance of the US over GB figures for military and violence (5); the greater American concern with matters of law and crime (6); the stronger American showing in business (7), in education (10), and in the embracement of grand abstractions, particularly those representing democratic ideals (14). Other findings suggest that a shift has occurred since the 1960s: the stronger showing of AmE than BrE in the social hierarchy category (4); the leapfrogging of BrE by AmE as the variety more oriented to family relationships (13); the loss of the British preference for abstract categories representing emotions and attitudes to the Americans (14); the dissipation of the British monopoly on the discoursal tendency towards indecisiveness and equivocation (15).

2. Do the results reflect the close historical, and current, relationship between Australia and New Zealand?

It is not unduly surprising that two Antipodean countries - whose Englishes have evolved in almost parallel fashion (Schneider 2007: 127) and whose residents affectionately refer to each other as 'cousins' (as in GloWbE-NZ: "The term 'crash comic' comes from our Australian cousins") - should yield so many similar results in the present study. Some of the most striking results were the consistent alignment of the AU and NZ frequencies for: all four items in the social hierarchy (4) category - for social class, upper class, middle class and working class - suggestive of similarly structured societies in the two countries; military and violence (5), suggestive of compatible attitudes towards gun-related violence, peacekeeping, military spending and the like; the arts and high culture (11); use of family-related terms (13). Other domains where AusE and NZE exhibit close frequencies are, in particular: socio-political issues as migration and equality (3); business (7); television consumption (8); use of masculine terms (13); use of terms denoting abstract concepts (14); ifs, buts, and modality (15). The picture that emerges is of two peoples whose lives and attitudes are for 
the most part very similar. There are however at least two striking differences: the far stronger education result for $\mathrm{NZ}$ than for $\mathrm{AU}$, which perhaps reflects inter alia the greater proportion of university degree holders in New Zealand than in Australia (4.10); and the considerably greater interest in religion in New Zealand (12).

3. Does the Kachruvian distinction between IC and OC countries provide a basis for interpreting the findings of the study, and if so for which categories? Do the findings suggest any further subgroupings within the OC?

The IC vs OC distinction looms large in the findings. In the case of sport (1) I have attributed the ascendancy of the IC countries to the availability of facilities and lifestyle differences. The predominance of the IC countries in the case of law and crime (6) I have ascribed to their established legal and judicial systems. Business (7) is dominated by the OC countries, most likely a reflection of the interest in these countries in their strong economic development. With science and technology (9) there is a division between the strong IC results for science, and conversely the strong OC results for technology. For ifs, buts and modality (15) the two circles evidence rhetorical differences, with the IC countries more prone to equivocation and hedging. In some cases the majority of $\mathrm{OC}$ countries exhibit a tendency that differentiates them from high frequency IC results, but there is an OC outlier: for arts (11) all OC countries except Hong Kong have frequencies lower than the IC; for emotions and attitudes (14) it is Singapore; and for auxiliary be and have (16) it is India.

A further finding that emerged from the study was that, within the OC, there was a tendency for the two Southeast Asian countries, Singapore and Hong Kong, on the one hand to be differentiated from India and Kenya on the other. As a potential source of explanations for this division it is tempting to invoke the concepts of 'developing' and 'Third World' countries, while exercising due caution with their acknowledged slipperiness. India and Kenya are generally regarded as developing nations (e.g. https:/en.wikipedia.org/wiki/Developing _country\#Developing_countries_according_to_International_Monetary_Fund), a classification determined by such criteria as industrialisation and per capita income levels and by Human Development Index ratings, and also as Third World nations (as determined by such additional criteria as poverty rates, infant mortality rates, economic stability, and the availability of basic human resources). The study provides ample evidence for the suggested subclassification of OC countries, with not only a number of cases where IN and KE together outscore SG and HK together - namely military and violence (5), personal refer- 
ence: family (13), abstract concepts: grand abstractions (14), and ifs, buts and modality (15) - but also, conversely, at least one case where SG and HK together outscore IN and KE together (the arts (11)). In other cases the co-patterning applies only to SG and HK (e.g. administration and politics (3)), or only to IN and KE (e.g. social hierarchy (4)).

4. Does Schneider's (2007) proposal of a dynamic evolutionary process in the formation of postcolonial Englishes provide a basis for interpreting any of the present study's findings, and if so for which categories?

The findings discussed in answer to Research Question 3 above, indicating the significance of the IC vs OC distinction, are related to the Schneider model in view of the evolutionary difference between the four IC countries (all of which have passed through all of Schneider's five phases), and the four OC countries (none of which has attained the level of evolutionary development of the IC countries, although Singapore appears to be getting close: see below).

In section 1, I cited studies supportive of the view that SingE is entering Schneider's fifth and final phase ('differentiation'). The findings of the present study provide further support for this view, specifically in the alignment of SingE - but not of the other OC varieties - with the IC varieties in some categories. Witness for example the Singaporean abandonment of OC-style collectivism in favour of individualism in the personal reference domain (13), and the IC-like readiness of Singaporeans to embrace talk about emotions and attitudes (14).

5. Do the frequencies for individual varieties reflect their national stereotypes and/or cultural values?

There are a number of clear cases of frequencies suggestive of national stereotypes and/or cultural values. The most striking case is Hong Kong, whose residents are often considered to be status-conscious, tech-savvy, obsessed with education and schooling, peace-loving (at least, prior to the 2019 protests), and to have respect for the cultural value of collectivism. These stereotypes are evoked respectively by the strong HK frequencies for social hierarchy (4), technology (9) and education (10), and by the low frequencies for military and violence (5) and personal reference: individual (13). GloWbE-US frequencies corroborate the stereotypical American passion for self-government and patriotism (with frequencies higher for patriotic, nation and citizens than those for the other IC varieties (3)), militarism (5), respect for justice (6), aversion to high culture (11), strong adherence to religious beliefs and practices (12), and capitalism-inspired individualism (13). Three stereotypically Australian cultural values 
are egalitarianism, individualism, and anti-intellectualism, reinforced respectively by the high AU frequencies for social hierarchy (4) and personal reference: individual (13), and by the low frequency for education (10). The study's findings paint a picture of the stereotypical Singaporean as, amongst other things, obsessed with personal wealth, as suggested by the high SG frequencies for rich and wealth in business (7), and as pragmatic, in their lack of interest in grand abstractions (14).

6. Are there correlations between GloWbE frequencies and statistics available for real world phenomena

There is a good deal of evidence of correlations between GloWbE frequencies and real world statistics which provide a fruitful source of explanations, but at the same time there are cases of non-correlation which caution us against making simplistic assumptions about direct mappings between language and 'reality'. For example, as we have seen, there is a strong correlation between the high HK frequencies for technology, the "tech-savvy" reputation of Honkongers, and statistical information on electronic and digital technology use in Hong Kong. Relative frequencies for Christianity-related items correlate strongly with the reported percentages of Christians per country. By contrast there are cases where a high incidence of something in the real world does not translate into an appetite for discussing it (as reflected in GloWbE frequencies), as for instance in the disconnect between the varietal frequencies for happiness (14) and country-bycountry rankings in the World Happiness Report, and between the relatively modest US frequency for suicide (6) and evidence of high suicide rates in the USA.

And then there were three subsidiary questions:

7. Do any of the results for the $\mathrm{OC}$ varieties reflect substrate influences and/or second-language acquisition simplification strategies?

The final category in the study, 'forms of the auxiliary verbs be and have' (16), produced results for the $\mathrm{OC}$ varieties that are suggestive of substrate influence. The dramatically rarer use of auxiliary be and have in the OC than the IC has, I have suggested, two possible explanations. The first relates to the tendency towards affixial marking of aspectual distinctions in OC substrate languages, and the second to simplification strategies - more specifically, auxiliary deletion - used in second-language acquisition. 
8. Is there any evidence of skewing in the GloWbE data that might affect results?

The category of sport (1) yielded two skewing issues which required the exercising of caution. The first issue involved GloWbE searches for a number of particular sports which confirmed LF's finding that their relatively high or low corpus frequencies were directly related to whether or not, or how commonly, they are played in the country under examination. My response to the danger that inclusion of these individual sports would skew the general findings for the category was to ignore them entirely, and instead to focus my attention on more general sports-related terms. The second issue involved the occurrence of a major event in the sampling period of the corpus, in this study the 2012 London Olympics, a likely factor in the surprisingly high British frequencies for sport (1). Another category to which the second issue was relevant was administration and politics (3), with high AU frequencies for climate change and global warming possibly influenced by the actions taken the Labor Government in mid-2012. In both cases I decided to simply recommend caution in the interpretation of results rather than deleting the entire category (1), or items within a category (3).

9. When is it legitimate to offer generalisations pertaining to entire categories, and when is it not?

Question 9 overlaps - at least partially - with Question 8. There were five categories for which there was no obvious real-world explanation for the potentially skewing effect of the frequencies for one or more items (as for example the skewing of the total frequencies in social hierarchy (4) by the high frequencies for one item, middle class). The categories were either small - social hierarchy (4), law and crime (6), mass media (8), and science and technology (9) - or very heterogeneous, making interpretation well-nigh impossible at a general level (administration and politics (3)). In all such cases I provided a table to facilitate discussion of the frequencies of individual category items.

To conclude, the availability of the GloWbE corpus, whose 2012/13 sampling period is a half-century on from the 1961 data used in Leech and Fallon's (1992) pioneering study, has enabled me to pursue a more up-to-date and wideranging study which both updates LF's findings and extends their application to a further six regional varieties of English. I hope that this study, in its quest to further articulate an answer to the question posed in the title of LF's paper (“Computer corpora - what do they tell us about culture?"), will provide an incentive for others to undertake corpus-based research on keywords, particularly in World Englishes. 


\section{Notes}

* This paper is dedicated to the memory of Geoffrey Leech, to whom we are indebted for his pioneering work in Corpus Linguistics. It was an early paper published by Leech and a colleague in this journal (Leech and Fallon 1992) that provided the inspiration for the present study.

1. A study based on linguistic contrasts is Oakes and Farrow (2007), who use the chi-squared test to find the vocabulary most typical of seven corpora, each representing the English used in a particular country: AmE (Frown); BrE (FLOB); AusE (ACE); IndE (Kolhapur); KenE (ICE-EA); NZE (Wellington); and Tanzanian English (ICE-EA). Oakes and Farrow's focus on vocabulary differences between corpora, rather than between cultures (as in Leech and Fallon 1992), results in essentially predictable findings - of a type that would be dismissed in cultural keyword studies as 'uninteresting' - such as that the terms typical of the different varieties are mostly names of people and places (e.g. for Australia Australia, Australian, Sydney, Aboriginal, Queensland, Melbourne, etc.).

2. At an earlier stage of the study, for each lexical item I had assigned a set of varietal scores ranging from eight for the highest frequency, to seven for the second highest, and so on, to one for the lowest frequency. I then totalled the scores for each category, to enable ordering of the varieties. I subsequently abandoned this system in view of the drawback that, with all items counting equally regardless of their frequencies, it gives equal weight to higher- and lower-frequency items.

3. According to a story published in The Straits Times (on August $9^{\text {th }}$ 2013) "the collective community spirit of the nascent nation of the 1960s will be eroded by the soaring individual well-being of a cosmopolitan and maturing Singapore" (https://www.straitstimes.com/singapore/will-singapores-collective-spirit-prevail).

\section{References}

Alsagoff Lubna and Ho Chee Lick. 1999. The grammar of Singapore English. In J. Foley et al. (eds.). English in new cultural contexts: Reflections from Singapore, 127-151. Singapore: Oxford University Press.

Berber-Sardinha, Tony. 2001. Comparing corpora with WordSmith keywords. The ESPecialist 22: 87-99.

Bolton, Kingsley. 2003. Chinese Englishes. A sociolinguistic history. Cambridge: Cambridge University Press. 
Chen, Chenghui. 2017. An intercultural analysis of the use of hedging by Chinese and Anglophone academic English writers. Applied Linguistics Review 8: $1-34$.

Clarke, David. 2002. Hong Kong art: Culture and decolonization. Durham, North Carolina: Duke University Press.

Davies, Mark and Robert Fuchs. 2015. Expanding horizons in the study of World Englishes with the 1.9 billion word Global Web-based English Corpus (GloWbE). English World-Wide 36: 1-28.

Dyrenfurth, Nick. 2015. Mateship: A very Australian history. Melbourne: Scribe Publications.

Ford, Clementine. 2018. Boys will be boys: Power, patriarchy and the toxic bonds of mateship. Sydney: Allen and Unwin.

Grieve, Jack, Douglas Biber, Eric Friginal and Tatiana Nekrasova. 2010. Variation among blog text types: A multi-dimensional analysis. In A. Mehler, S. Sharoff and M. Santini (eds.). Genres on the Web: Corpus studies and computational models, 303-322. New York: Springer-Verlag.

Gupta, R. S. 2001. English in post-colonial India. An appraisal. In B. Moore (ed.). "Who's centric now?" The present state of post-colonial Englishes, 148-164. Melbourne: Oxford University Press.

Hackert, Stephanie, Dagmar Deuber, Carolin Biewer and Michaela Hilbert. 2013. Modals of possibility, ability and permission in selected New Englishes. In M. Huber and J. Mukherjee (eds.). Corpus linguistics and variation in English: Focus on non-native Englishes (Studies in Variation, Contacts and Change in English 13). http://www.helsinki.fi/varieng/journal/ volumes/13/hackert_deuber_biewer_hilbert/

Hofland, Knut and Stig Johansson. 1982. Word frequencies in British and American English. Bergen: Norwegian Computing Centre for the Humanities.

Hofstede, Geert. 2001. Culture's consequences: Comparing values, behaviors, institutions and organizations across nations. Thousand Oaks, CA.: Sage.

Hong, Jasper. 2014. A feature-based study of English trainee teachers' treatment of Singapore English. IATL Reinvention: An International Journal of Undergraduate Research 7(1). http://www.warwick.ac.uk/reinventionjournal/issues/volume7issue1/hong

Hornadge, Bill. 1980. The Australian slanguage. Sydney: Methuen.

Hyland, Ken. 1997. Language attitudes at the handover: Communication and identity in 1997 Hong Kong. English World-Wide 18: 191-210. 
Kachru, Braj. 1985. Standards, codification, and sociolinguistic realism: The English language in the outer circle. In R. Quirk and H. G. Widdowson (eds.). English in the world, 11-30. Cambridge: Cambridge University Press.

Kachru, Braj. 1994. English in South Asia. In R. Burchfield (ed.). The Cambridge history of the English language. Vol. 5. English in Britain and overseas: Origins and development, 497-553. Cambridge: Cambridge University Press.

Klimova, Blanka. 2014. Using tentative language in English. Procedia Social and Behavioural Sciences 116: 661-663.

Leech, Geoffrey and Roger Fallon. 1992. Computer corpora - what do they tell us about culture? ICAME Journal 16: 29--50.

Leimgruber, Jakob. 2011. Singapore English. Language and Linguistics Compass 5: 47-62.

Loureiro-Porto, Lucía. 2017. ICE vs GloWbE: Big data and corpus compilation. World Englishes 36: 448-470.

Matthews, Stephen and Virginia Yip. 2011. Cantonese: A comprehensive gram$\operatorname{mar}\left(2^{\text {nd }}\right.$ ed.). New York: Routledge.

Mazzon, Gabriella. 2019. Variation in the expression of stance across varieties of English. World Englishes 38: 1-13.

Moore, Bruce. 2008. Speaking our language: The story of Australian English. South Melbourne: Oxford University Press.

Mukherjee, Joybrato and Tobias Bernaisch. 2015. Cultural keywords in context: A pilot study of linguistic acculturation in South Asian Englishes. In P. Collins (ed.). Grammatical change in English world-wide, 411-435. Amsterdam: John Benjamins.

Nelson, Gerald. 2015. Response to Davies and Fuchs. English World-wide 36: 38-40.

Nolan, Melanie. 2007. The reality and myth of New Zealand egalitarianism: Explaining the pattern of a labour historiography at the edge of empires. Labour History Review 72: 113-134.

Oakes, Michael P. 2003. Contrasts between US and British English of the 1990s. In E. H. Oletsky and B. Lewandowska-Tomaszczyk (eds.). Research and scholarship in integration processes: Poland - USA - EU, 213-222. Lodz: Lodz University Press. 
Oakes, Michael P. and Malcolm Farrow. 2007. Use of the chi-squared test to examine vocabulary differences in English language corpora representing seven different countries. Literary and Linguistic Computing 22: 85-99.

Ooi, Vincent B. Y. 2000. Asian or Western realities? Collocations in Singaporean-Malaysian English. In J. M. Kirk (ed.). Corpora galore: Analyses and techniques in describing English, 73-89. Amsterdam: Rodopi.

Patel, Vikram, Chinthanie Ramasundarahettige, Lakshimi Vijayakumar, J. S. Thakur, Vendhan Gajalakshmi and Gopalkrishna Gururaj. 2012. Suicide mortality in India: A nationally representative survey. The Lancet 379: 2343-2351.

Percillier, Michael. 2016. World Englishes and second language acquisition: Insights from Southeast Asian Englishes. Amsterdam: Benjamins.

Rayson, Paul, Geoffrey Leech and Mary Hodges. 1997. Social differentiation in the use of English vocabulary: Some analyses of the conversational component of the British National Corpus. International Journal of Corpus Linguistics 2: 133-152.

Richards, Jack, C. 1974. Error analysis: Perspectives on second language acquisition. London: Longman.

Rosenthal, Doreen, Richard Bell, Andreas Demetriou and Anastasia Efklides. 1989. From collectivism to individualism: The acculturation of Greek immigrants in Australia. International Journal of Psychology 24: 57-71.

Sahgal, Anju. 1991. Patterns of language use in a bilingual setting in India. In J. Cheshire (ed.). English around the World: Sociolinguistic patterns, 299307. Cambridge: Cambridge University Press.

Schneider, Edgar. 2007. Postcolonial English: Varieties of English around the World. Cambridge: Cambridge University Press.

Somjee, A. H. and Geeta Somjee. 1995. Singapore: A super pragmatic society. In A. H. Somjee and G. Somjee (eds). Development success in Asia Pacific. An exercise in normative-pragmatic balance, 17-51. Hampshire: Macmillan.

Squires, Lauren. 2010. Enregistering internet language. Language in Society 39: 457-492.Stubbs, Michael. 1996. Text and corpus analysis: Computer assisted studies of language and culture. Oxford: Blackwell.

Squires, Lauren. 2010. Enregistering internet language. Language in Society 39: 457-492.

Stubbs, Michael. 1996. Text and corpus analysis: Computer assisted studies of language and culture. Oxford: Blackwell. 
Tan, Kenneth P. 2012. The ideology of pragmatism: Neo-liberal globalisation and political authoritarianism in Singapore. Journal of Contemporary Asia 42: 67-92.

Tan, Peter K. W. 2012. English in Singapore. International Journal of Language, Translation and Intercultural Communication 1: 123-138.

Teubert, Wolfgang. 2001. A province of a federal superstate, ruled by an unelected bureaucracy - keywords of the Euro-sceptic discourse in Britain. In A. Musolff, C. Good, P. Points and R. Whittlinger (eds.). Attitudes towards Europe: Language in the unification, 45-86. Burlington: Ashgate.

Wang, Paul. 2003. Assessing consumer vanity in Australia and China. ANZMAC 2003 Conference Proceedings. Adelaide 1-3 December 2003. https://opus.lib.uts.edu.au/bitstream/10453/2217/3/2003000846.pdf.

Wee, C. J. W. 1999. "Asian Values", Singapore, and the third way: Re-working individualism and collectivism. Sojourn: Journal of Social Issues in Southeast Asia 14: 332-358.

Wierzbicka, Anna. 1997. Understanding cultures through their key words: English, Russian, Polish, German, and Japanese. New York: Oxford University Press.Williams, Raymond. 1976. Keywords: A vocabulary of culture and society. London: Fontana.

Wierzbicka, Anna. 1997. Understanding cultures through their key words: English, Russian, Polish, German, and Japanese. New York: Oxford University Press. Williams, Raymond. 1976. Keywords: A vocabulary of culture and society. London: Fontana. 